University of Nebraska - Lincoln

DigitalCommons@University of Nebraska - Lincoln

Uniformed Services University of the Health

Sciences

U.S. Department of Defense

2011

\title{
The United States Army Ocular Teleconsultation program 2004 through 2009
}

\author{
Michael J. Mines \\ Walter Reed Army Medical Center, Michael.mines@amedd.army.mil \\ Kraig S. Bower \\ Johns Hopkins University \\ Charles M. Lappan \\ Southern Regional Medical Command \\ Robert A. Mazzoli \\ Madigan Army Medical Center \\ Ronald K. Poropatich \\ U.S. Army Medical Research and Materiel Command
}

Follow this and additional works at: https://digitalcommons.unl.edu/usuhs

Part of the Medicine and Health Sciences Commons

\footnotetext{
Mines, Michael J.; Bower, Kraig S.; Lappan, Charles M.; Mazzoli, Robert A.; and Poropatich, Ronald K., "The United States Army Ocular Teleconsultation program 2004 through 2009" (2011). Uniformed Services University of the Health Sciences. 30.

https://digitalcommons.unl.edu/usuhs/30

This Article is brought to you for free and open access by the U.S. Department of Defense at DigitalCommons@University of Nebraska - Lincoln. It has been accepted for inclusion in Uniformed Services University of the Health Sciences by an authorized administrator of DigitalCommons@University of Nebraska Lincoln.
} 


\title{
The United States Army Ocular Teleconsultation program 2004 through 2009
}

\author{
MICHAEL J. MINES, KRAIG S. BOWER, CHARLES M. LAPPAN, ROBERT A. MAZZOLI, AND \\ RONALD K. POROPATICH
}

- PURPOSE: To describe the United States Army Ocular Teleconsultation program and all consultations received from its inception in July 2004 through December 2009. - DESIGN: Retrospective, noncomparative, consecutive case series.

- METHODS: All 301 consecutive ocular teleconsultations received were reviewed. The main outcome measures were differential diagnosis, evacuation recommendations, and origination of consultation. Secondary measures included patient demographics, reason for consultation, and inclusion of clinical images.

- RESULTS: The average response time was 5 hours and 41 minutes. Most consultations originated from Iraq (58.8\%) and Afghanistan (18.6\%). Patient care-related requests accounted for $94.7 \%$ of consultations; nonphysicians submitted $26.3 \%$ of consultations. Most patients (220/285; 77.2\%) were United States military personnel; the remainder included local nationals and coalition forces. Children accounted for 23 consultations (8.1\%). Anterior segment disease represented the largest grouping of cases $(129 / 285 ; 45.3 \%)$; oculoplastic problems represented nearly one quarter $(68 / 285 ; 23.9 \%)$. Evacuation was recommended in $123(43.2 \%)$ of 285 cases and in $21(58.3 \%)$ of 36 cases associated with trauma. Photographs were included in $38.2 \%$, and use was highest for pediatric and strabismus $(83.3 \%)$ and oculoplastic $(67.6 \%)$ consultations. Consultants facilitated evacuation in $87(70.7 \%)$ of 123 consultations where evacuation was recommended and avoided unnecessary evacuations in $28(17.3 \%)$ of 162 consultations.

- CONCLUSIONS: This teleconsultation program has brought valuable tertiary level support to deployed providers, thereby helping to facilitate appropriate and timely referrals, and in some cases avoiding unnecessary evacuation. Advances in remote diagnostic and imaging technology could further enhance consultant support to

AJO.com Supplemental Material available at AJO.com

Accepted for publication Jan 13, 2011.

From the Ophthalmology Service, Walter Reed Army Medical Center, Washington, DC (M.J.M.); The Wilmer Eye Institute, Johns Hopkins University, Baltimore, Maryland (K.S.B.); the Uniformed Services University of the Health Sciences, Bethesda, Maryland (M.J.M., K.S.B., R.A.M.); the Southern Regional Medical Command, Fort Sam Houston, Texas (C.M.L.); the Ophthalmology Service, Madigan Army Medical Center, Tacoma, Washington (R.A.M.); and the U.S. Army Medical Research and Materiel Command, Fort Detrick, Maryland (R.K.P.).

Inquiries to Michael J. Mines, Ophthalmology Service, Walter Reed Army Medical Center, 6900 Georgia Avenue NW, Room 1F-18, Washington, DC 20307-5001; e-mail: Michael.mines@amedd.army.mil distant providers and their patients. (Am J Ophthalmol 2011;152:126-132. Published by Elsevier Inc.)

T ELEMEDICINE USES TELECOMMUNICATION AND INformation technologies to provide and support healthcare when distance separates participants. ${ }^{1}$ The United States military medical system, caring for globally distributed patients often located in austere and dangerous environments, is in a unique position to make use of telemedicine. As a specialty heavily reliant on visual information, ophthalmology is amenable to telemedicine applications. ${ }^{2-5}$ Teleconsultation, a method within telemedicine, focuses on assisting a remote provider by offering expert opinions and diagnostic support regarding the treatment of a patient. ${ }^{6}$ Because medical providers accompanying deployed military personnel may have limited experience in specialty areas like ophthalmology, teleconsultation is of particular interest.

Realizing both the need and potential benefit of such a teleconsultation system, the United States Army implemented a formal electronic mail (e-mail) teleconsultation program to give deployed military providers rapid access to specialty opinions. ${ }^{7}$ The ocular teleconsultation program, a component of this multispecialty system, began in July 2004. Since then, teleophthalmology consultations have constituted the third largest specialty group of the Army system, making up $5 \%$ of all consultations. ${ }^{6,7}$ In this article, we review the ocular teleconsultation program from its inception through December 2009.

\section{METHODS}

THE OCULAR TELECONSULTATION PROGRAM IS A COMPOnent of a larger e-mail consultation system described elsewhere (see Supplemental Figure 1, available at AJO. com). ${ }^{6,7}$ The program utilizes a pre-existing e-mail communication system known as Army Knowledge Online. Incoming messages are routed automatically from Army Knowledge Online to a global e-mail system (Microsoft Outlook; Microsoft Corporation, Redmond, Washington, USA) used by all United States-based specialty providers. Because of the nonsecure nature of this system, identifying patient information is excluded from the consultation by the sender (name, date of birth, etc.). The advantage of the system is that United States military providers world- 
TABLE 1. United States Army Ocular Teleconsultation Program Diagnostic Categories by Subgroup, Included Photographs, Evacuation Recommendation, and Trauma Association

\begin{tabular}{|c|c|c|c|c|c|}
\hline Diagnostic Category of Consult & $\begin{array}{l}\text { No. by } \\
\text { Group }\end{array}$ & $\begin{array}{c}\text { No. of } \\
\text { Consultations } \\
(\mathrm{N}=285)\end{array}$ & $\begin{array}{l}\text { Consultation Requests } \\
\text { with Photographs } \\
\text { by Category }\end{array}$ & $\begin{array}{l}\text { Evacuation } \\
\text { Recommended by } \\
\text { Category }\end{array}$ & $\begin{array}{c}\text { Trauma Consultations } \\
\text { by Category }\end{array}$ \\
\hline Anterior segment & & $129(45.3 \%)$ & $49(38.0 \%)$ & $48(37.2 \%)$ & 13 (10.0\%) \\
\hline Corneal surface disease & 30 & & & & \\
\hline Conjunctivitis & 20 & & & & \\
\hline Superficial conjunctival lesions & 19 & & & & \\
\hline Refractive surgery related & 14 & & & & \\
\hline Conjunctival or corneal foreign body & 12 & & & & \\
\hline Dryness & 9 & & & & \\
\hline Keratoconjunctivitis & 7 & & & & \\
\hline Ocular myiasis & 4 & & & & \\
\hline Anterior segment intraocular lesion & 3 & & & & \\
\hline Corneal transplantation & 2 & & & & \\
\hline Red eye related & 2 & & & & \\
\hline Pigmented conjunctival lesion & 2 & & & & \\
\hline Subconjunctival hemorrhage & 2 & & & & \\
\hline Chemosis & 1 & & & & \\
\hline Corneal ectasia & 1 & & & & \\
\hline Glaucoma & 1 & & & & \\
\hline Oculoplastic, adnexa, and orbit & & $68(23.9 \%)$ & $46(67.6 \%)$ & $20(29.4 \%)$ & $8(11.8 \%)$ \\
\hline Eyelid disease & 22 & & & & \\
\hline $\mathrm{R} / \mathrm{O}$ orbital mass or fracture & 12 & & & & \\
\hline Noninflammatory eyelid lesion & 6 & & & & \\
\hline Noninfectious periocular skin changes & 6 & & & & \\
\hline Herpes zoster dermatitis related & 5 & & & & \\
\hline Eyelid myokymia and blepharospasm & 5 & & & & \\
\hline Herpes simplex dermatitis related & 4 & & & & \\
\hline Ptosis and/or dermatochalasis & 2 & & & & \\
\hline Infectious periocular skin changes & 1 & & & & \\
\hline Lymphangioma vs. neurofibromatosis & 1 & & & & \\
\hline Enucleation & 1 & & & & \\
\hline Canaliculitis vs dacryocystitis & 1 & & & & \\
\hline Orbitopathy, thyroid related & 1 & & & & \\
\hline Facial nerve palsy & 1 & & & & \\
\hline Retina & & $27(9.5 \%)$ & $3(11.1 \%)$ & $18(66.7 \%)$ & $7(25.9 \%)$ \\
\hline Retinal detachment related & 10 & & & & \\
\hline Trauma-related retinopathy (not RD) & 7 & & & & \\
\hline Nontraumatic retinopathy & 7 & & & & \\
\hline Posterior intraocular lesion & 3 & & & & \\
\hline Neuro-ophthalmology & & $24(8.4 \%)$ & $3(12.5 \%)$ & $10(41.7 \%)$ & $2(8.3 \%)$ \\
\hline Anisocoria or pupil defect & 7 & & & & \\
\hline Migraine & 6 & & & & \\
\hline Diplopia & 5 & & & & \\
\hline Visual field defect & 3 & & & & \\
\hline Photophobia & 1 & & & & \\
\hline Optic nerve & 1 & & & & \\
\hline Idiopathic intracranial hypertension & 1 & & & & \\
\hline Uveitis & & $15(5.3 \%)$ & $3(20.0 \%)$ & $10(66.7 \%)$ & $4(26.7 \%)$ \\
\hline Anterior uveitis & 10 & & & & \\
\hline Posterior uveitis & 5 & & & & \\
\hline Vision & & $13(4.6 \%)$ & $0(0.0 \%)$ & $11(84.6 \%)$ & $2(15.4 \%)$ \\
\hline \multirow[t]{2}{*}{ Blurred vision } & 13 & & & & \\
\hline & & & & \multicolumn{2}{|c|}{ (Continued on next page) } \\
\hline
\end{tabular}


TABLE 1. United States Army Ocular Teleconsultation Program Diagnostic Categories by Subgroup, Included Photographs, Evacuation Recommendation, and Trauma Association (Continued)

\begin{tabular}{|c|c|c|c|c|c|}
\hline Diagnostic Category of Consult & $\begin{array}{l}\text { No. by } \\
\text { Group }\end{array}$ & $\begin{array}{l}\text { No. of } \\
\text { Consultations } \\
(\mathrm{N}=285)\end{array}$ & $\begin{array}{c}\text { Consultation Requests } \\
\text { with Photographs } \\
\text { by Category }\end{array}$ & $\begin{array}{l}\text { Evacuation } \\
\text { Recommended by } \\
\text { Category }\end{array}$ & $\begin{array}{c}\text { Trauma Consultations } \\
\text { by Category }\end{array}$ \\
\hline Pediatrics and strabismus & & $6(2.1 \%)$ & $5(83.3 \%)$ & $6(100 \%)$ & $0(0.0 \%)$ \\
\hline Retinoblastoma & 2 & & & & \\
\hline Strabismus & 2 & & & & \\
\hline Buphthalmos & 1 & & & & \\
\hline Congenital glaucoma & 1 & & & & \\
\hline Optometric & & $3(1.1 \%)$ & $0(0.0 \%)$ & $0(0.0 \%)$ & $0(0.0 \%)$ \\
\hline Optometry & 3 & & & & \\
\hline Total & 285 & 285 & 109 (38.2\%) & $123(43.2 \%)$ & $36(12.6 \%)$ \\
\hline
\end{tabular}

wide can consult an ophthalmologist or optometrist by e-mailing a single address. The system is monitored by both a clinical and technical manager. Specific volunteer military ophthalmologists and optometrists are identified to respond to consultation requests. Because of the worldwide nature of the United States military mission, deployed providers may not be in the same time zone as consultants. These differing time zones were considered in the design of the system. Consultants stationed in various locations around the world ensure that whenever a consultation is initiated, a consultant is available. The local provider obtains history and other pertinent data from the patient. If desired, digital images focusing on the area of interest can be submitted with the consultation request. Because consultation information is deidentified by the local provider to ensure patient confidentiality, a unique patient code is generated and maintained by the submitting provider. The information and images are sent via e-mail to a central e-mail address where automated message routing forwards the message to consultants. The date and time of the consultation and responses are recorded by the technical manager, and reminders sent if the consultation request is not responded to within 24 hours.

All consultations and related e-mail responses from July 2004 through December 2009 were reviewed by 1 author (M.J.M.) for the specific criteria listed below. Results were entered into an Access 2007 database (Microsoft Corporation) for analysis. Consultations initially were analyzed to determine response time, geographic origin of consultation request, and type of consultation (administrative vs patient care). Requests not pertaining to a specific patient (e.g., medical resources available in a location, policy issues, etc.) were categorized as administrative. Those consultations related to patient care were analyzed further to determine (1) patient demographics (age, gender, military status); (2) professional training of the requesting provider; (3) whether other specialty consultants (e.g., dermatology) also participated in the answering the consultation request; (4) diagnostic category or differential diagnosis of the problem in question; (5) whether the consultation request was trauma related; (6) reason for the consultation request (diagnostic support vs management recommendation vs knowledge transfer vs arrange evacuation); (7) whether photographs were included; (8) whether evacuation was recommended; and (9) whether the consultant's response either facilitated or avoided an evacuation.

For analysis, consultations were grouped into diagnostic categories that roughly parallel the major ophthalmologic subspecialties: anterior segment (includes cataract, glaucoma, cornea, and external diseases), oculoplastic (includes eyelid, adnexa, and orbit), retina and vitreous, neuro-ophthalmology, uveitis, pediatrics and strabismus, vision, and optometric. The differential diagnosis was determined as accurately as possible based on all the information contained within each consultation record. This included the presentation in the initial consultation request, photographs or imaging studies if applicable, the opinions of the consultant(s), and feedback from the referring providers when available. Business practice dictated that consultations were deidentified for consultants; therefore, final diagnoses generally were not available. Consultations consequently were subdivided based on the most likely diagnosis at the time of consultation. Because in certain instances overlap was unavoidable (e.g., floaters could fall under retina or vision), in cases potentially spanning 2 groups or more, the most likely diagnosis determined the specific category assigned. A consultation was considered trauma related if the requester or the consultant considered trauma a likely factor in their differential diagnosis.

Evacuation was defined as the movement of patients to the nearest ophthalmologist or optometrist for additional care or diagnostics. Depending on the geographic location of the patient, that care might have been within the same country, a country in the region, or in the United States. Consultations where evacuation was recommended were analyzed further to determine if the consultant's recommendation facilitated the evacuation. An evacuation was considered facilitated if: (1) the requester was reluctant to evacuate the patient 
TABLE 2. United States Army Ocular Teleconsultation Program Trauma-Related Consultations

\begin{tabular}{|c|c|c|c|c|c|c|}
\hline $\begin{array}{l}\text { Trauma-Related } \\
\text { Consultations }\end{array}$ & No. & $\begin{array}{c}\text { Trauma } \\
\text { Consultations by } \\
\text { Location }\end{array}$ & No. & $\begin{array}{c}\text { Evacuation } \\
\text { Recommended }\end{array}$ & $\begin{array}{l}\text { Consulted } \\
\text { Within } 24 \mathrm{~h}\end{array}$ & $\begin{array}{c}\text { Consulted } \\
\text { Within } 7 \text { days }\end{array}$ \\
\hline \multirow[t]{4}{*}{ Combat related } & 18 & & & 10 & 2 & 9 \\
\hline & & Eye & 12 & & & \\
\hline & & Orbit & 9 & & & \\
\hline & & Both & 3 & & & \\
\hline \multirow[t]{4}{*}{ Accidental } & 18 & & & 11 & 5 & 10 \\
\hline & & Eye & 16 & & & \\
\hline & & Orbit & 6 & & & \\
\hline & & Both & 4 & & & \\
\hline Total & 36 & & 36 & 21 (58.3\%) & 7 (19.4\%) & 19 (52.8\%) \\
\hline
\end{tabular}

(because of the physical risk of doing so or the disruption the patient's loss would create); (2) the requester's stated plan did not include evacuation; (3) the requester did not state a plan; or (4) the requester asked whether the patient's condition warranted evacuation. Consultations where the requester's plan included evacuation were excluded. Consultations where evacuation was not recommended likewise were analyzed to determine whether the consultant's recommendation avoided evacuation. In these consultations, an evacuation was considered avoided only if the requester specifically asked whether the patient's condition warranted evacuation.

Patient-related consultations also were analyzed to determine the underlying reason or type of information sought by the requester. Diagnostic support consisted of consultations requesting assistance with both a differential diagnosis and management recommendations. Consultations in which the requester had developed a differential diagnosis and was seeking assistance with treatment options were categorized as management recommendations. Knowledge transfer consultations referred to questions relating to a specific patient (spectacle fabrication resources for a patient in need, whether a patient with a particular stable diagnosis could be deployed), but not an active illness or injury. Arrange evacuation consultations were those in which the requester already had determined the need to move the patient to a higher level of care and used the teleconsultation system to facilitate the process.

\section{RESULTS}

FROM JULY 2004 THROUGH DECEMBER 2009, A TOTAL OF 301 ocular consultation requests were received. All consultation requests were answered with an average response time of 5 hours and 41 minutes (range, 5 minutes to 80 hours). The number of different volunteer consultants answering requests gradually increased from 5 in 2004 to 28 in 2009. In 2009, the average number of consultants responding to each request was 1.5 , up from 1.0 per consultation in the initial year of the program (see Supplemental Table 1, available at AJO.com). The large majority of consultations originated from Iraq $(58.8 \% ; 177 / 301)$ and Afghanistan $(18.6 \% ; 56 / 301)$, with the remainder representing a broad geographic distribution (see Supplemental Table 2, available at AJO.com). Consultation requests from Afghanistan gradually rose and in 2009 exceeded consultations originating in Iraq. Consultations from Navy afloat likewise rose in recent years (see Supplemental Figure 2, available at AJO.com). Sixteen consultation requests (5.3\%) sought general or administrative information. The remaining 285 consultation requests $(94.7 \%)$ were patient-related consultations and are described more fully below.

Physicians accounted for most consultations (73.7\%; 210/285) and represented a diverse range of specialties and subspecialties. Nonphysician providers included physician assistants, optometrists, medical corpsmen, and 1 dentist (see Supplemental Table 3, available at AJO.com). Requests concerning United States military patients constituted $220(77.2 \%)$ of 285 consultations; $36.8 \%$ (105/285) of patients were United States Army soldiers, and an equal percentage $(36.8 \% ; 105 / 285)$ represented the other 3 Department of Defense uniformed services and Coast Guard combined (see Supplemental Table 4, available at AJO.com). Of the non-United States military patients, local nationals were the largest group and accounted for 37 (13.0\%) of all 285 consultations. Patient age was provided in 205 (71.9\%) of 285 consultation requests. Of these, the mean age was 28 years (range, 2 to 67 years). Childrenpatients younger than 18 years or identified as childrenaccounted for 23 consultation requests $(8.1 \%)$. There were $250(87.7 \%)$ male patients and $34(11.9 \%)$ female patients, and for 4 patients (1.4\%), the gender was unspecified. These percentages total more than $100 \%$ because several consultation requests asked about more than 1 patient.

The overwhelming majority (90.9\%) of requests sought information concerning management recommendations $(37.9 \% ; 108 / 285)$ or diagnostic support $(53.0 \% ; 151 / 285)$. 
Direct requests to arrange evacuation accounted for only 2.1\% (6/285) of requests (see Supplemental Figure 3, available at AJO.com).

Questions concerning anterior segment issues represented nearly one half of all cases $(129 / 285 ; 45.3 \%)$, and oculoplastic diseases represented approximately one quarter of requests $(68 / 285 ; 23.9 \%)$. However, all disease categories were represented, and the range of clinical problems was very broad (Table 1). A number of consultations spanned other body systems and were sent to consultants of other specialties in addition to ophthalmology. Twenty-eight $(9.8 \%)$ consultation requests also were responded to by consultants from dermatology, neurology, infectious disease, or orthopedics.

If desired, providers had the ability to include photographs with consultation requests; 109 (38.2\%) of the 285 patient-related consultation requests included photographs. The likelihood of photographs being included varied depending on the diagnostic category (Table 1 ).

We received 36 consultation requests related to trauma $(12.6 \%)$. Of these, evacuation was recommended by the consultant in $58.3 \%(21 / 36$; Table 2$)$. In 249 non-trauma-related consultations, evacuation was recommended in 102 cases $(41.0 \%)$. Considering all patient-related cases, evacuation was recommended in $123(43.2 \%)$ of 285 consultations. Evacuation statistics are given in Table 1. Consultants' recommendations facilitated 87 patient evacuations. Although the consultation program did not require it, feedback from requesters provided confirmation of this in 28 of those 87 evacuations. For consultations in which evacuation was not recommended, the consultant's recommendation helped to avoid evacuation in 28 cases.

\section{DISCUSSION}

BOTH THE GEOGRAPHIC ISOLATION AND AUSTERE ENVIronment of military deployment can dramatically limit communication between far forward providers and rear echelon medical specialists. Unlike community- or hospital-based care, traditional consultative services can be strained or nonexistent. Likewise, evacuation of a military patient not only entails the risks commonly associated with stateside emergency transportation, but also often includes greater logistical coordination while under the threat of hostile enemy action. Furthermore, although the dollar value of evacuation must be considered, the immediate cost lies in the loss of the patient to the organization and the obligation of transportation assets when they may be needed elsewhere. These factors have led to the exploration of information technology as a solution.

With the advent of e-mail, informal methods to support deployed medical care developed. Technological advances also allowed more formal consultation programs to begin. ${ }^{8}$ Understanding its importance, the United States Army
Medical Department instituted its first telemedicine program in 1992. ${ }^{6}$ The United States Navy did likewise. ${ }^{9,10}$ Since then, various military telemedicine efforts have arisen to support deployed providers and their patients. ${ }^{11-14}$ Based on the early success of e-mail consultation, the United States Army Medical Department approved an official policy permitting its use in 2005 with subsequent policy revisions in 2007 and 2009. ${ }^{15}$

The benefits of e-mail teleconsultation-expert second opinions to remote locations over a low-cost system-are not limited to military environments. Many of the elements that make it advantageous in a military setting also apply to care in the developing world. Wootton describes 5 such programs supporting developing world healthcare. ${ }^{16}$ Our system and several of these share functional similarities. Although all our consultants are active duty military personnel, like most of the civilian program consultants, our specialists volunteer to participate. Additionally, our system makes use of automated message routing to direct consultations from requester to specialist. ${ }^{17,18}$ Unlike other systems, however, our service routes each consultation request and answer to every specialist. This facilitates a more rapid response if a particular consultant is unavailable, notifies all participants that a consultation request has been answered, allows multiple responses to a consultation request if desired, and avoids the need for a call schedule.

Because the funding and specialty resources available to create a teleconsultation system typically reside in the developed location, care must be taken during its creation and operation to ensure that the services offered address the needs of those who will be seeking assistance. As the recipients of teleconsultation support, Bonnardot and Rainis, working at a remote Antarctic station, provide a unique perspective on the desired traits of a teleconsultation program. ${ }^{19}$ They argue that, to be useful, the system must be reachable at any time, both the communication method and the expert assistance must be reliable, and the advice must be tailored to the specific environment of the requester. We are fortunate that the design of our system, based on the underlying Army Knowledge Online e-mail system, ensures accessibility and reliable communication. Likewise, because our consultants are located around the world, a specialist generally is within 2 time zones of the requester. Also, because multiple consultants receive each request, the likelihood of specialist availability is increased. The third requirement, tailored advice, is the most challenging to meet. Despite familiarity with the deployed environment and the military aspects of the setting, the particular nature of the patient, provider, and resources on hand make many consultations distinct. Although this study did not measure how best to address this aspect, it became clear that specialist experience answering consultations and dialogue with the requester concerning local capabilities led to determining the best course of action for a particular patient. Others have had similar experiences. ${ }^{20}$ 
Given United States military deployment patterns since 2004, it is not surprising that United States Army personnel and Iraq constituted, respectively, the highest percentage of consultations by type of patient and location. In this setting, however, $13.0 \%$ of consultations concerned local civilians and $8.1 \%$ concerned children, indicating that care of the local population is not an infrequent activity in conflict. Anterior segment and eyelid and external disease questions accounted for nearly three quarters of all consultations and $87 \%$ of attached photographs. By percentage, however, these were less likely to be recommended for evacuation compared with retina, neuro-ophthalmology, vision-related, and pediatric concerns. The inability to perform an adequate examination, either by the requester or the consultant via e-mail, likely contributed to this higher tendency for recommending evacuation and highlights the need for better deployable diagnostic and imaging capabilities.

Physicians represented $73.7 \%$ of providers seeking a consultation. The breadth of specialties reflects the diversity of provider billets in a deployed environment. Relatively few ophthalmologists or optometrists submitted teleconsultations. Presumably, they either did not need the service or had contacts through other channels. Sixteen consultation requests $(5.3 \%)$ sought general or administrative information. This is similar to results from a review of e-mail consultations originating from a family practice clinic setting in which $12 \%$ of the questions were general in nature, whereas the bulk of consultations were about a specific patient. ${ }^{21}$

Requesters sought information from within 4 categories. More than one half of consultations (53.0\%) asked for diagnostic support. When combined with management recommendations, the 2 groups account for $90.9 \%$ of consultations. These data likely reflect that for many of the uninitiated, the ophthalmology patient can be daunting; however, they also reveal an interest in support, if available. By comparison, requests to arrange evacuation numbered $6(2.1 \%)$. Procedurally, other mechanisms exist to notify receiving sites of evacuated patients, so in these cases, the teleconsultation system was used adjunctively.

In a military setting, one might reasonably expect a high percentage of trauma-related consultations. However, trauma-related consultations, whether combat associated or accidental, and spanning minor to severe, accounted for only 36 of 285 requests (Table 2 ). This is seemingly at odds with published reports indicating that serious combatrelated ocular injury alone represents $13 \%$ of all injuries, and indeed, is at odds with our own experience at Walter Reed Army Medical Center. ${ }^{22}$ However, relatively few trauma-related consultations occurred within 24 hours of injury, suggesting that providers did not need teleconsul- tative assistance in acute cases or that other mechanisms are in place to aid them. We suspect both to be the case, because these providers are all trained in trauma triage and they are supported by a robust military evacuation system.

Admittedly, it is difficult to gauge whether this program effectively facilitated necessary evacuations or avoided unnecessary ones because final determination of patient status, and what the outcome would have been had the consultation service not been available, are unknown. Despite these constraints, it was clear that the requester often sought the consultant's recommendation to help determine the need for evacuation. In fact, in $23.5 \%$ of all consultations (67/285), the requester specifically asked for guidance regarding whether to evacuate the patient. Given the weight attributed to the consultant's opinion, it is not surprising, then, that the consultant's recommendation facilitated transfer in $87(70.7 \%)$ cases.

This study has several limitations. Although it does include all ocular consultation requests sent to the teleconsultation program, it likely does not include all ocularrelated consultation requests sent from the field; informal, person-to-person requests are still available and likely were used. The study also is retrospective and descriptive in nature. Additionally, consultations are deidentified, and therefore there is no way to evaluate the final diagnosis or outcome. Finally, although feedback from requesters is uniformly positive-indicating that the system goes some way in meeting their needs-there is no formal assessment mechanism. A survey system, similar to one described by Wootton and associates, would be useful. ${ }^{23}$

United States military forces currently are operating in multiple regions around the world. Their medical mission includes caring for American military personnel and allied forces. It also includes humanitarian care for local nationals and indigenous populations. The widely dispersed nature of these forces frequently preclude the ready availability of on-the-ground specialty care. Teleconsultation offers a unique ability to assist distant providers as they care for patients. Likewise, teleconsultation can decrease the cost and risk of moving patients in dangerous or austere environments. However, limitations exist. Although current technology is helpful, it is just beginning to allow remote patient evaluation.

As communication technology continues to advance, teleconsultation likely will expand, not only in military settings, but in civilian environments as well. Teleconsultation can extend the reach of finite physician resources to remote populations and underserved subgroups. Adapting teleconsultation programs to the needs of those seeking medical support will ensure that timely and useful advice is available to assist distance providers and their patients.

THE OPINIONS EXPRESSED IN THIS ARTICLE ARE THOSE SOLELY OF THE AUTHORS AND DO NOT REPRESENT THE VIEWS OR official policies of the United States Army or Department of Defense. The authors indicate no financial support or financial conflict of interest. Involved in Design and conduct of study (M.J.M., K.S.B., R.A.M.); Collection, management, analysis, and interpretation of data (M.J.M., K.S.B., C.L., R.A.M., 
R.K.P.); preparation (M.J.M., K.S.B., R.A.M.), review, and approval (M.J.M., K.S.B., C.L., R.A.M., R.K.P.) of the manuscript. This study was reviewed and determined to be an exempt protocol by the Walter Reed Army Medical Center Department of Clinical Investigation Institutional Review Board and adhered to the Declaration of Helsinki and all applicable federal and state laws in the United States. The authors thank each consultant who volunteered their time and expertise to this program. Without their efforts and dedication, this article, and more importantly this teleconsultation program, would not be possible.

\section{REFERENCES}

1. Field MJ. Telemedicine: A Guide to Assessing Telecommunications in Health Care. Division of Health Care Services, Institute of Medicine. Washington, DC: National Academy Press, 1996:16. Available at: http://www.nap.edu/openbook. php?record_id=5296\&page=16. Accessed May 28, 2010.

2. Flowers CW Jr, Baker RS, Khanna S, et al. Teleophthalmology: rationale, current issues, future directions. Telemed J 1997;3(1):43-52.

3. Li HK. Telemedicine and ophthalmology. Surv Ophthalmol 1999;44(1):61-72.

4. Lamminen H, Voipio V, Ruohonen K, Uusitalo H. Telemedicine in ophthalmology. Acta Ophthalmol Scand 2003; 81(2):105-109.

5. Tang RA, Morales M, Ricur G, Schiffman JS. Telemedicine for eye care. J Telemed Telecare 2005;11(8):391-396.

6. Poropatich RK, DeTreville R, Lappan C, Barrigan CR. The U.S. Army telemedicine program: general overview and current status in Southwest Asia. Telemed J E Health 2006;12(4):396-408.

7. McManus J, Salinas J, Morton M, et al. Teleconsultation program for deployed soldiers and healthcare professionals in remote and austere environments. Prehosp Disaster Med 2008;23(3):210-216.

8. Crowther JB, Poropatich R. Telemedicine in the U.S. Army: case reports from Somalia and Croatia. Telemed J 1995;1(1):73-80.

9. Melcer T, Crann B, Hunsaker D, et al. A retrospective evaluation of the development of a telemedicine network in a military setting. Mil Med 2002;167(6):510-515.

10. Reed C, Burr R, Melcer T. Navy telemedicine: a review of current and emerging research models. Telemed J E Health 2004;10(3):343-356.

11. Gomez E, Poropatich R, Karinch MA, Zajtchuk J. Tertiary telemedicine support during global military humanitarian missions. Telemed J 1996;2(3):201-210.

12. Navein J, Hagmann J, Ellis J. Telemedicine in support of peacekeeping operations overseas: an audit. Telemed J 1997;3(3):207214.
13. Walters TJ. Deployment telemedicine: The Walter Reed Army Medical Center experience. Mil Med 1996;161(9): 531-536.

14. Calcagni DE, Clyburn CA, Tomkins G, et al. Operation Joint Endeavor in Bosnia: telemedicine systems and case reports. Telemed J 1996;2(3):211-224.

15. Use of Army Knowledge Online (AKO) Email to Conduct Electronic Medical Consultation-OTSG/MEDCOM Policy Memo 09-034, dated 4 June 2009. Available at: https:// www.qmo.amedd.army.mil/credentialing/09_034.pdf. Accessed May 28, 2010.

16. Wootton R. Telemedicine support for the developing world. J Telemed Telecare 2008;14(3):109-114.

17. Wootton R. Design and implementation of an automatic message-routing system for low-cost telemedicine. J Telemed Telecare 2003;9(suppl)1:S44-S47.

18. Swinfen P, Swinfen R, Youngberry K, Wootton R. A review of the first year's experience with an automatic messagerouting system for low-cost telemedicine. J Telemed Telecare 2003;9(suppl)2:S63-S65.

19. Bonnardot L, Rainis R. Store-and-forward telemedicine for doctors working in remote areas. J Telemed and Telecare 2009; 15(1):1-6.

20. Vassallo DJ, Hoque F, Roberts MF, et al. An evaluation of the first year's experience with a low-cost telemedicine link in Bangladesh. J Telemed Telecare 2001;7(3):125-138.

21. Bergus GR, Sinift SD, Randall CS, Rosenthal DM. Use of an E-mail curbside consultation service by family physicians. J Fam Pract 1998;47(5):357-360.

22. Weichel ED, Colyer MH, Ludlow SE, Bower KS, Eiseman AS. Combat ocular trauma visual outcomes during Operations Iraqi and Enduring Freedom. Ophthalmology 2008; 115(12):2235-2245.

23. Wootton R, Youngberry K, Swinfen P, Swinfen R. Prospective case review of a global e-health system for doctors in developing countries. J Telemed Telecare 2004;10(Suppl)1: 94-96. 


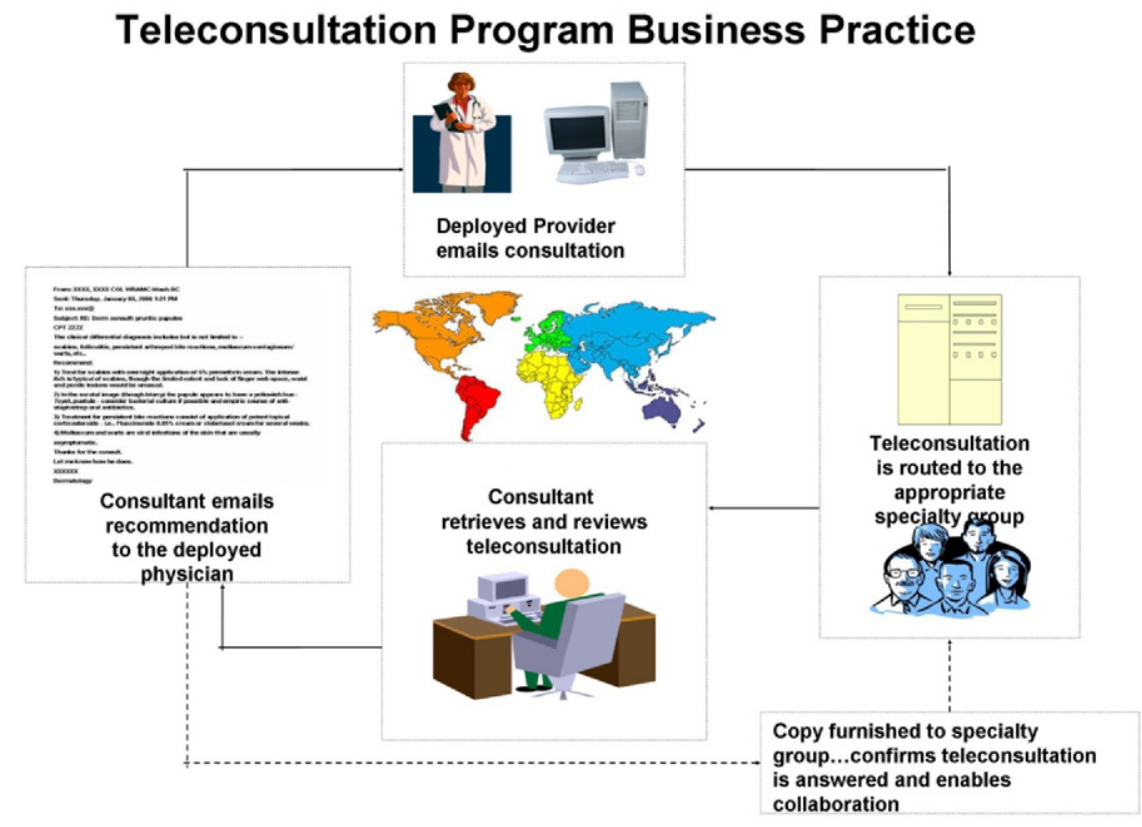

SUPPLEMENTAL FIGURE 1. United States Army Ocular Teleconsultation system work flow design.

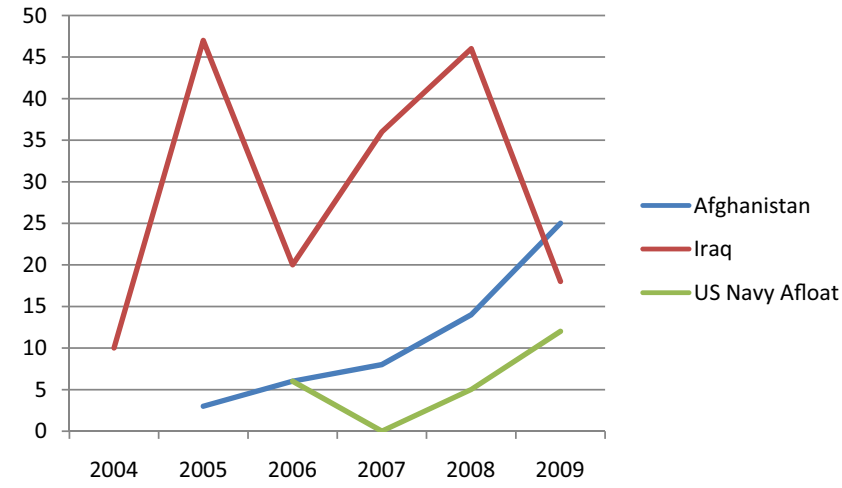

SUPPLEMENTAL FIGURE 2. Graph showing United States Army Ocular Teleconsultation consultations from Iraq, Afghanistan, and the United States Navy afloat per year.

\section{Type of Consult, \% of Total}

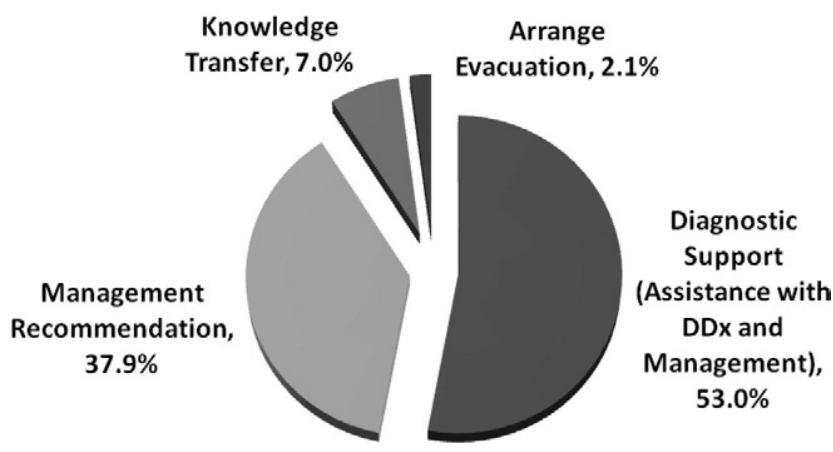

SUPPLEMENTAL FIGURE 3. Pie chart showing United States Army Ocular Teleconsultation consultations categorized by type of information sought by the requester $(n=285)$. 
SUPPLEMENTAL TABLE 1. United States Army Ocular Teleconsultation Program Consultations per Calendar Year (January 1 through December 31); Ophthalmology Consultations Began in July 2004 (total $\mathrm{N}=301$ )

\begin{tabular}{|c|c|c|c|c|c|}
\hline $\begin{array}{c}\text { Program } \\
\text { Year }\end{array}$ & $\begin{array}{c}\text { Different } \\
\text { Volunteer } \\
\text { Consultants }\end{array}$ & $\begin{array}{c}\text { No. of } \\
\text { Consultations }\end{array}$ & $\begin{array}{c}\text { Total } \\
\text { Consultant } \\
\text { Responses }\end{array}$ & $\begin{array}{c}\text { Average } \\
\text { Responses } \\
\text { per } \\
\text { Consultation }\end{array}$ & $\begin{array}{c}\text { Average } \\
\text { Response } \\
\text { Time } \\
\text { (h:min) }\end{array}$ \\
\hline 2004 & 5 & 11 & 11 & 1.0 & $6: 45$ \\
\hline 2005 & 10 & 59 & 83 & 1.4 & $7: 31$ \\
\hline 2006 & 10 & 37 & 46 & 1.2 & $6: 55$ \\
\hline 2007 & 16 & 54 & 64 & 1.2 & $4: 53$ \\
\hline 2008 & 19 & 77 & 141 & 1.8 & 5:02 \\
\hline 2009 & 28 & 63 & 97 & 1.5 & $4: 34$ \\
\hline Total & & 301 & & & $5: 41$ \\
\hline
\end{tabular}

SUPPLEMENTAL TABLE 3. United States Army Ocular Teleconsultation Program Consultations by Requesting Provider $(n=285)$

\begin{tabular}{lrrrr}
\hline Requesting Provider (Training/ & & & \multicolumn{2}{c}{ Photographs } \\
\cline { 5 - 6 } Specialty) & No. & \multicolumn{1}{c}{$\%$} & No. & $\%$ \\
\hline Physician & 210 & 73.7 & 73 & 34.8 \\
Family practice & 16 & 5.6 & 4 & 25.0 \\
Internal medicine & 8 & 2.8 & 3 & 37.5 \\
Emergency medicine & 8 & 2.8 & 4 & 50.0 \\
Ophthalmology & 3 & 1.1 & 2 & 66.7 \\
General surgery & 3 & 1.1 & 1 & 33.3 \\
Pediatrics & 3 & 1.1 & 0 & 0.0 \\
Interventional cardiology & 2 & 0.7 & 1 & 50.0 \\
Infectious disease & 1 & 0.4 & 1 & 100 \\
Neurosurgery & 1 & 0.4 & 1 & 100 \\
Obstetrics-gynecology & 1 & 0.4 & 1 & 100 \\
Otolaryngology & 1 & 0.4 & 1 & 100 \\
Dermatology & 1 & 0.4 & 0 & 0.0 \\
Geriatrics & 1 & 0.4 & 0 & 0.0 \\
Neurology & 1 & 0.4 & 0 & 0.0 \\
Preventive medicine & 1 & 0.4 & 0 & 0.0 \\
Unspecified MD/DO & 159 & 55.8 & 54 & 34.0 \\
Physician assistant & 51 & 17.9 & 25 & 49.0 \\
Medic/independent & 11 & 3.9 & 6 & 54.5 \\
corpsman & & & & \\
Optometrist & 9 & 3.2 & 4 & 44.4 \\
Unspecified & 3 & 1.1 & 1 & 33.3 \\
Dentist & 1 & 0.4 & 0 & 0.0 \\
Total & 285 & 100 & 109 & 38.2 \\
\hline
\end{tabular}

SUPPLEMENTAL TABLE 2. Geographic Origin of Consultations Received by the United States Army Ocular Teleconsultation Program 2004 through $2009(\mathrm{~N}=301)$

\begin{tabular}{lrr}
\hline \multicolumn{1}{c}{ Originating Location } & No. & $\%$ \\
\hline Iraq & 177 & 58.8 \\
Afghanistan & 56 & 18.6 \\
Navy afloat & 23 & 7.6 \\
Qatar & 17 & 5.6 \\
Kuwait & 6 & 2.0 \\
Kyrgyzstan & 5 & 1.7 \\
United Arab Emirates & 4 & 1.3 \\
Continental United States & 3 & 1.0 \\
Egypt & 3 & 1.0 \\
Djibouti & 2 & 0.7 \\
Kosovo & 2 & 0.7 \\
Bahrain & 1 & 0.3 \\
Germany & 1 & 0.3 \\
Honduras & 1 & 0.3 \\
Total & 301 & 100 \\
\hline DO - Doctor of Osteopathy & MD - Medical doctor. & \\
\hline
\end{tabular}

SUPPLEMENTAL TABLE 4. United States Army Ocular Teleconsultation Program Consultations by Patient Status $(n=285)$

\begin{tabular}{lrc}
\hline \multicolumn{1}{c}{ Status of Patient } & No. & $\%$ \\
\hline United States military & & \\
Total United States military & 220 & $77.2 \%$ \\
Army & 105 & $36.8 \%$ \\
Marines & 56 & $19.6 \%$ \\
Air Force & 28 & $9.8 \%$ \\
Navy & 20 & $7.0 \%$ \\
Unspecified & 9 & $3.2 \%$ \\
Coast Guard & 1 & $0.4 \%$ \\
Cadet & 1 & $0.4 \%$ \\
Non-United States military & & \\
Total Non-United States military & 65 & $22.8 \%$ \\
$\quad$ Local nationals & 37 & $13.0 \%$ \\
Contractors & 15 & $5.3 \%$ \\
Coalition forces & 12 & $4.2 \%$ \\
$\quad$ United States civilian evacuee & 1 & $0.4 \%$ \\
Total & 285 & $100 \%$ \\
\hline
\end{tabular}

